\title{
Front Matter: Volume 9046
}

, "Front Matter: Volume 9046," Proc. SPIE 9046, 2013 International Conference on Optical Instruments and Technology: Optoelectronic Measurement Technology and Systems, 904601 (20 December 2013); doi: $10.1117 / 12.2054693$

SDIE Event: International Conference on Optical Instruments and Technology (OIT2013), 2013, Beijing, China 


\title{
2013 International Conference on Optical Instruments and Technology
}

\section{Optoelectronic Measurement Technology and Systems}

\author{
Hwa-Yaw Tam \\ Kexin Xu \\ Hai Xiao \\ Jigui Zhu \\ Editors
}

17-19 November 2013

Beijing, China

Sponsored by

CIS-China Instrument and Control Society (China)

SPIE

Cooperating Organizations

Opto-Electronic-Mechanic Technology and System Integration Chapter, CIS (China) • Committee on Optoelectronic Technology, COS (China) • Optical Instrument Chapter, CIS (China) • Beijing Institute of Technology (China) • Tianjin University (China) - Zhejiang University (China) - Tsinghua University (China) • Nankai University (China) • Capital Normal University (China) • Nanjing University (China) - Shanghai Jiaotong University (China) • Beijing University of Posts and Telecommunications (China) - Chongqing University (China) - University of Shanghai for Science and Technology (China) - Beijing Hamamatsu Photon Techniques Inc. (China) • Instrument Society of America (United States) • Institute of Measurement and Control (United Kingdom) • Hong Kong Institution of Engineers (China) • The Society of Measurement and Control (Japan)

Published by

SPIE

\section{Volume 9046}


The papers included in this volume were part of the technical conference cited on the cover and title page. Papers were selected and subject to review by the editors and conference program committee. Some conference presentations may not be available for publication. The papers published in these proceedings reflect the work and thoughts of the authors and are published herein as submitted. The publisher is not responsible for the validity of the information or for any outcomes resulting from reliance thereon.

Please use the following format to cite material from this book:

Author(s), "Title of Paper," in 2013 International Conference on Optical Instruments and Technology: Optoelectronic Measurement Technology and Systems, edited by Hwa-Yaw Tam, Kexin Xu, Hai Xiao, Jigui Zhu, Proceedings of SPIE Vol. 9046 (SPIE, Bellingham, WA, 2013) Article CID Number.

ISSN: 0277-786X

ISBN: 9780819499646

Published by

SPIE

P.O. Box 10, Bellingham, Washington 98227-0010 USA

Telephone +1 3606763290 (Pacific Time) · Fax +1 3606471445

SPIE.org

Copyright (C) 2013, Society of Photo-Optical Instrumentation Engineers.

Copying of material in this book for internal or personal use, or for the internal or personal use of specific clients, beyond the fair use provisions granted by the U.S. Copyright Law is authorized by SPIE subject to payment of copying fees. The Transactional Reporting Service base fee for this volume is $\$ 18.00$ per article (or portion thereof), which should be paid directly to the Copyright Clearance Center (CCC), 222 Rosewood Drive, Danvers, MA 01923. Payment may also be made electronically through CCC Online at copyright.com. Other copying for republication, resale, advertising or promotion, or any form of systematic or multiple reproduction of any material in this book is prohibited except with permission in writing from the publisher. The CCC fee code is 0277-786X/13/\$18.00.

Printed in the United States of America.

Publication of record for individual papers is online in the SPIE Digital Library.

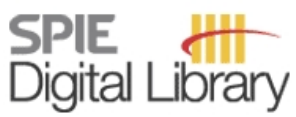

SPIEDigitallibrary.org

Paper Numbering: Proceedings of SPIE follow an e-First publication model, with papers published first online and then in print and on CD-ROM. Papers are published as they are submitted and meet publication criteria. A unique, consistent, permanent citation identifier (CID) number is assigned to each article at the time of the first publication. Utilization of CIDs allows articles to be fully citable as soon as they are published online, and connects the same identifier to all online, print, and electronic versions of the publication. SPIE uses a six-digit CID article numbering system in which:

- The first four digits correspond to the SPIE volume number.

- The last two digits indicate publication order within the volume using a Base 36 numbering

system employing both numerals and letters. These two-number sets start with 00, 01, 02, 03, 04, $05,06,07,08,09,0 A, 0 B \ldots 0 Z$, followed by 10-1Z, 20-2Z, etc.

The CID Number appears on each page of the manuscript. The complete citation is used on the first page, and an abbreviated version on subsequent pages. Numbers in the index correspond to the last two digits of the six-digit CID Number. 


\title{
Contents
}

\author{
ix Symposium Committee \\ xi Conference Committee \\ xiii Introduction
}

\section{SESSION 1 OPTOELECTRONIC TECHNOLOGY IN METROLOGY}

904602 Study of the instrument transfer function of a free-form optics metrology system: SCOTS (Invited Paper) [9046-52]

T. Su, A. Maldonado, P. Su, P. Zhou, J. H. Burge, College of Optical Sciences, The Univ. of Arizona (United States)

904603 Research of Temporal Speckle Pattern Interferometry for in-plane measurement [9046-4] G. Li, Z. Gao, Y. Deng, Beijing Jiaotong Univ. (China)

904604 High precision double-interferometry displacement measurement by waveform transforming based on FFT [9046-83]

Y. Wang, F. Xie, S. Ma, Beijing Jiaotong Univ. (China)

904605 Numerical simulation and experimental verification of extended source interferometer [9046-84]

Y. Hou, L. Li, S. Wang, Beijing Institute of Technology (China); X. Wang, China North Industries Navigation and Control Technology Research Institute (China); H. Zang, Q. Zhu, Beijing Institute of Technology (China)

904606 Four-step spatial phase-shifting lateral shearing interferometry by a crossed grating and a linear grating [9046-15]

Z. Guo, Y. Song, J. Wang, Z. Li, A. He, Nanjing Univ. of Science and Technology (China)

\section{SESSION 2 OPTOELECTRONIC MEASUREMENT AND DETECTION}

904607 Crosstalk reduction of a color fringe projection system based on multi-frequency heterodyne principle [9046-6]

Z. Zhang, Y. XU, Y. Liu, Hebei Univ. of Technology (China)

904608 Research on light scattering from randomly rough metal and dielectric surfaces with Monte Carlo method based on method of moment [9046-14]

K. Yan, Nanjing Univ. of Science and Technology (China) and Xi'an Technological Univ. (China); H. Chen, Z. Li, Nanjing Univ. of Science and Technology (China)

904609 A simple instrument for measuring the linear birefringence changes and the phase retardation in electro-optic crystals [9046-19]

Y. Zhang, W. Li, H. Liu, Jilin Jianzhu Univ. (China) 
9046 0A Design and analysis on front-end electronics of InGaAs photoelectric detector [9046-59] X. Liu, Univ. of Science and Technology of China (China)

9046 OB UGR (Unified Glare Rating) measuring system based on digital camera platform [9046-76] W. Wang, Z. Cen, Y. Yang, Zhejiang Univ. (China)

$90460 \mathrm{C}$ Optimized design and error analysis of optical system for heterodyne grating interferometry (Invited Paper) [9046-63]

C. Lin, S. Yan, C. Wei, G. Wang, P. Zou, National Univ. of Defense Technology (China)

9046 OD Fluctuation elimination of fringe pattern by using empirical mode decomposition [9046-8] Z. Zhang, E. Zhang, Hebei Univ. of Technology (China)

$9046 \mathrm{OE} \quad$ Texture blending on 3D models using casual images [9046-33]

$X$. Liu, Shenzhen Institute of Information Technology (China) and Shenzhen Univ. (China); X. Liu, A. Li, Shenzhen Univ. (China); J. Liu, H. Wang, Shenzhen Institute of Information Technology (China)

9046 OF A nonintrusive method for the measurement of infrared characteristics from engine exhaust plume [9046-46]

X. Xiao, Univ. of Chinese Academy of Sciences (China) and Shanghai Institute of Technical Physics (China); Y. Wang, B. Miao, Shanghai Institute of Technical Physics (China); J. Lang, Univ. of Chinese Academy of Sciences (China) and Shanghai Institute of Technical Physics (China); S. Wang, X. Zhuang, Shanghai Institute of Technical Physics (China); F. Zhou,

Consultant (China); J. Wang, Shanghai Institute of Technical Physics (China)

9046 OG The influence of atmospheric turbulence on 3D flash lidar range imagery [9046-58]

Y. Zhao, S. Han, W. Zhao, P. Wang, W. Xia, Beijing Institute of Technology (China)

\section{SESSION 4 OPTOELECTRONIC INSTRUMENTS AND SYSTEMS II}

$9046 \mathrm{OH}$ The application of variable universe fuzzy PID controller in computer-aided alignment of lithography projector [9046-66]

M. Zhang, M. Zheng, Y. Li, Beijing Institute of Technology (China)

9046 Ol Design of DSP-based high-power digital solar array simulator [9046-57]

Y. Zhang, Z. Liu, W. Tong, J. Feng, Y. Ji, Hefei Univ. of Technology (China)

$90460 \mathrm{~J}$ Prospects for a four-level super-radiant laser with ultra-narrow linewidth at $1469 \mathrm{~nm}$ based on cesium [9046-56]

Y. Wang, C. Dai, Z. Wu, National Institute of Metrology (China); X. Li, Shenzhen Academy of Metrology and Quality Inspection (China)

9046 OK Progress report towards a digital mirror device based confocal microscopic system [9046-93]

D. Yi, S. Lin, S. Huang, S. Xie, Motic China Group Co. Ltd. (China) 
$9046 \mathrm{OL} \quad$ Measuring the shape of membrane mirror based on Shack-Hartmann wavefront sensor [9046-10]

Y. Huang, B. Yang, M. Tang, X. Chen, Soochow Univ. (China)

9046 OM Volume phase holographic grating used for beams combination of RGB primary colors [9046-12]

H. Liu, X. Zhang, M. Tang, Soochow Univ. (China)

9046 ON Design and analysis of multi-electrodes distribution for shaping of electrostatic stretched membrane mirror [9046-13]

L. Jiang, X. Wei, B. Yang, M. Tang, Soochow Univ. (China)

904600 Observation of transmission enhancement phenomena in a laser resonant cavity [9046-17] P. Zhang, S. L. Zhang, N. Liu, Z. L. Zeng, L. XU, Y. D. Tan, Tsinghua Univ. (China)

9046 OP The design and implementation of high accuracy digital control semiconductor laser constant current source [9046-18]

T. Zhao, C. Huang, Beijing Univ. of Posts and Telecommunications (China)

$90460 Q \quad$ Online measurement system for the surface inclination of metal workpieces [9046-23]

P. Yin, C. Sun, P. Wang, Q. Yang, Tianjin Univ. (China)

9046 OR Application of the blind signal separation method for phase-shifting interferometry with random phase shifts [9046-25]

F. Zeng, H. Gu, Q. Tan, Tsinghua Univ. (China)

9046 OS The beam delivery modeling and error sources analysis of beam stabilization system for lithography [9046-28]

J. Wang, Shanghai Institute of Optics and Fine Mechanics (China) and Univ. of Chinese Academy of Sciences (China); L. Huang, L. Hou, Shanghai Institute of Optics and Fine Mechanics (China); G. He, Shanghai Institute of Optics and Fine Mechanics (China) and Univ. of Chinese Academy of Sciences (China); B. Ren, A. Zeng, H. Huang, Shanghai Institute of Optics and Fine Mechanics (China)

9046 OT High dynamic range image acquisition method for 3D solder paste measurement [9046-29] X. Li, C. Sun, P. Wang, Tianjin Univ. (China); Y. Xu, Shanghai FuDae Al Technology Co. Ltd. (China)

9046 OU Study on optical 3D angular deformations measurement [9046-30]

Y. Gao, X. Wang, Z. Huang, J. Yang, National Univ. of Defense Technology (China)

$9046 \mathrm{OV}$ The design of color spectrophotometer based on diffuse illumination and compatible SCE/SCl geometric condition [9046-36]

K. Yuan, Zhejiang Univ. (China) and China Jiliang Univ. (China); H. Yan, Zhejiang Univ. (China); S. Jin, China Jiliang Univ. (China) 
9046 OW Research on the measurement technology and evaluation method of photobiological safety [9046-37]

C. Dai, Z. Wu, National Institute of Metrology (China); B. Chen, National Institute of Metrology (China) and Beijing Institute of Technology (China); Y. Wang, National Institute of Metrology (China); X. Li, Shenzhen Academy of Metrology and Quality Inspection (China); L. Fu, Beijing Institute of Technology (China)

9046 OX An innovative method of calculating target angle based on laser echo in laser imaging system [9046-39]

H. Sun, Beijing Institute of Technology (China); Q. Luo, Xi'an Modern Control Technology Institute (China); Y. Yang, J. Cao, Q. Hao, Beijing Institute of Technology (China)

9046 OY Straightness measurement system based on phase sensitive detection technique [9046-40] P. Huang, Y. Li, H. Wei, Tsinghua Univ. (China)

$90460 Z$ A laser frequency and power control system in an atomic Talbot-Lau interferometer [9046-42]

T. Yang, Z. Hu, L. Qi, BeiHang Univ. (China)

904610 Research on modern test system for resolution of white-light sighting telescope [9046-47] R. Liu, Z. Xiao, Z. An, P. Wen, X. Zhang, Changchun Univ. of Science and Technology (China)

904611 The research and development of the non-contact detection of the tubing internal thread with a line structured light [9046-49]

Y. Hu, Beijing Institute of Technology (China); Y. Xu, National Institute of Metrology (China); Q. Hao, Y. Hu, Beijing Institute of Technology (China)

904612 Optimized phase encoding for optical compressive sensing imaging [9046-51] J. Sun, F. Xu, Soochow Univ. (China)

904613 Curve fitting for standard lamp of spectral irradiance based on RBFNN [9046-61] B. Chen, Beijing Institute of Technology (China); C. Dai, Z. Wu, National Institute of Metrology (China); L. Fu, Beijing Institute of Technology (China)

904614 The current status and development of OD measurement technique [9046-62] M. Zhang, R. Zhang, Univ. of Shanghai for Science and Technology (China); W. Dai, $X$. Yuan, Shanghai Cohere Electronic Technology Co., Ltd. (China)

904615 The measurement system of birefringence and Verdet constant of optical fiber [9046-67] Y. Huang, L. Chen, Q. Guo, F. Pang, J. Wen, Y. Shang, T. Wang, Shanghai Univ. (China)

904616 Design of stabilization system for Medium Wave Infrared laser power [9046-73] Z. Ding, L. Wang, X. Shi, J. Xun, Xidian Univ. (China)

904617 Evaluating the damage process of dynamic target by high-energy laser in ocean environment [9046-75]

J. Wang, D. Ye, No. 713 Research Institute of China shipbuilding Industry Corp. (China) 
904618 Method of measurement laser beam wavefront and characterization on focal plane [9046-77]

M. Liu, X. Wang, Changchun Univ. of Science and Technology (China); B. Wang, Y. Jiang, Changchun Institute of Optics, Fine Mechanics and Physics (China)

904619 Off-line inspection method of microlens array for illumination homogenization in DUV lithography machine [9046-78]

F. Zhang, Shanghai Institute of Optics and Fine Mechanics (China) and Univ. of Chinese Academy of Sciences (China); J. Zhu, Shanghai Institute of Optics and Fine Mechanics (China); B. Yang, L. Huang, Shanghai Institute of Optics and Fine Mechanics (China) and Univ. of Chinese Academy of Sciences (China); X. Hu, Y. Xiao, Shanghai Institute of Optics and Fine Mechanics (China); H. Huang, Shanghai Institute of Optics and Fine Mechanics (China) and Univ. of Chinese Academy of Sciences (China)

$90461 \mathrm{~A}$ The initial point of collimator CCD imagine calibration by pyramid prism [9046-80] Z. Wang, China Jiliang Univ. (China) and National Institute of Metrology (China); S. Jin, China Jiliang Univ. (China); W. Wang, X. Zhu, National Institute of Metrology (China)

9046 1B The studying of solar cell process by using optoelectronic measurement system [9046-81] H. Wang, F. Lang, J. Shi, G. Li, Z. Hu, J. Xiong, Tianwei Yingli New Energy Resources Co., Ltd. (China)

9046 1C Spot image based multi-field wavefront retrieval [9046-82]

X. Chen, W. Shen, Soochow Univ. (China)

9046 1D Accuracy study of time delay estimation techniques in laser pulse ranger [9046-85] J. Yang, X. Wang, Y. Gao, National Univ. of Defense Technology (China)

9046 1E A CCD based approach to size and complex refractive index determination of absorbing droplet using rainbow scattering [9046-88]

Q. Pan, Nanjing Univ. of Information Science \& Technology (China)

9046 IF Optimized laser beam widths meter calibration system: precisely positioning of detector measurement plane [9046-90]

Y. Wang, Beijing Institute of Technology (China) and National Institute of Metrology (China); Q. Wang, Beijing Institute of Technology (China); C. Ma, National Institute of Metrology (China)

9046 1G Design of a high-accuracy bi-grating imaging instrument for non-dispersive imaging [9046-91]

W. Zhang, L. Liu, S. Sun, X. Zeng, Q. Lu, Guangxi Univ. (China)

$90461 \mathrm{H} \quad$ An optical fibre laser characteristics measuring system [9046-94]

J. Ni, C. Wang, Shandong Academy of Sciences (China); L. Zhang, Shandong Tianli Drying Technology and Equipment Co., Ltd. (China); J. Guo, H. Qi, Z. Sun, M. Wang, Shandong Academy of Sciences (China); G. D. Peng, The Univ. of New South Wales (Australia)

904611 Step-height measurement with a low coherence interferometer using continuous wavelet transform [9046-96]

Z. Jian, T. Suzuki, S. Choi, O. Sasaki, Niigata Univ. (Japan) 
$90461 \mathrm{~J}$ Measurement system for large size laser beam intensity distribution based on CCD diffuse transmission imaging [9046-98]

M. Pang, Univ. of Electronic Science and Technology of China (China) and China Academy of Engineering Physics (China); J. Rong, Univ. of Electronic Science and Technology of China (China); X. Yuan, X. Gao, S. Zhou, China Academy of Engineering Physics (China)

Author Index 


\title{
Symposium Committee
}

\author{
General Chairs \\ Songlin Zhuang, University of Shanghai for Science and Technology \\ (China) \\ William H. Arnold, ASML US, Inc. (United States) \\ Conference Cochairs \\ Yuri Chugui, New Siberia Academy of Sciences (Russian Federation) \\ Arthur Chiou, National Yang-Ming University (Taiwan, China) \\ Liwei Zhou, Beijing Institute of Technology (China) \\ Shenghua Ye, Tianjin University (China) \\ Yimo Zhang, CIS/Tianjin University (China) \\ Technical Program Chair \\ Guofan Jin, Tsinghua University (China) \\ Technical Program Cochairs \\ Jinxue Wang, Raytheon Company (United States) \\ Tiegen Liu, Tianjin University (China) \\ Local Organizing Committee Chair \\ Youhua Wu, China Instrument and Control Society (China) \\ Local Organizing Committee Cochairs \\ Guoqiang Ni, Beijing Institute of Technology (China) \\ Daoyin Yu, Tianjin University (China) \\ Yanbiao Liao, Tsinghua University (China) \\ Yulin Xi, Beijing Hamamatsu Photon Techniques Inc. (China) \\ General Secretary \\ Youhua Wu, China Instrument and Control Society (China) \\ Administrative Vice General Secretary \\ Yu-nan Sun, Beijing Institute of Technology (China)
}


Vice General Secretaries

Wei Xue, Beijing Institute of Technology (China)

Qun Hao, Beijing Institute of Technology (China)

Yuejin Zhao, Beijing Institute of Technology (China)

Qionghui Feng, University of Shanghai for Science and Technology (China)

Cunlin Zhang, Capital Normal University (China)

Local Organizing Committee

Changming Zhao, Beijing Institute of Technology (China)

Zheng You, Tsinghua University (China)

Yumei Wen, Chongqing University (China)

Hongda Chen, Institute of Semiconductors (China)

Shangzhong Jin, China Jiliang University (China)

Zhiping Zhou, Peking University (China)

Xuping Zhang, Nanjing University (China)

Libo Yuan, Harbin Engineering University (China)

Chunqing Gao, Beijing Institute of Technology (China)

Shiqiao Qin, National University of Defense Technology (China)

Tian Lan, Beijing Institute of Technology (China)

Cuiling Li, Beijing Institute of Technology (China)

Liquan Dong, Beijing Institute of Technology (China) 


\title{
Conference Committee
}

\author{
Conference Chairs
}

Hwa-Yaw Tam, Hong Kong Polytechnic University (Hong Kong, China)

Kexin Xu, Tianjin University (China)

Hai Xiao, University of Missouri (United States)

Jigui Zhu, Tianjin University (China)

Program Committee

Jian Wang, Focused Photonics (Hangzhou), Inc. (China)

Xiang Peng, Shenzhen University (China)

Changku Sun, Tianjin University (China)

Fajie Duan, Tianjin University (China)

Bukem Bilen, Bogazici University (Turkey)

Weiqian Zhao, Beijing Institute of Technology (China)

Aaron H. P. Ho, Chinese University of Hong Kong (Hong Kong, China)

Shangzhong Jin, China Jiliang University (China)

Lianqing Zhu, Beijing Information Science and Technology University (China)

Osami Sasaki, Niigata University (Japan)

Weihong Bi, Yanshan University (China)

Takamasa Suzuki, Niigata University (Japan)

Fengzhong Dong, Hefei Institute of Physical Science (China)

Weihu Zhou, Academy of Opto-electronics (China)

Young-Geun Han, Hanyang University (Korea, Republic of)

Jiubin Tan, Harbin Institute of Technology (China)

Changyuan Yu, National University of Singapore (Singapore)

Qibo Feng, Beijing Jiaotong University (China)

Yuanhong Yang, Beihang University (China)

Liandong Yu, Hefei University of Technology (China)

Julian Chi Chiu Chan, Nanyang Technological University (Singapore)

Tong Sun, City University London (United Kingdom)

Baiou Guan, Jinan University (China)

Emily Jianzhong Hao, Institute for Infocomm Research (Singapore)

Yange Liu, Nankai University (China)

Liyang Shao, Carleton University (Canada)

Yunqi Liu, Shanghai University (China)

Bo Dong, Institute for Infocomm Research (Singapore)

Chunliu Zhao, China Jiliang University (China)

Xuguang Huang, South China Normal University (China)

Bo Liu, Nankai University (China)

Yiping Wang, University of Southampton (United Kingdom)

Aping Zhang, Zhejiang University (China)

Li Pei, Beijing Jiaotong University (China) 
Bomin Su, Dunhuang Research Institute (China)

Junchang Yang, Shaanxi Research Institute of Cultural Relics Protection (China)

Qinghui Li, Shanghai Institute of Optics and Fine Mechanics (China)

Quan Wei, Sichuan Museum (China)

Xisheng Gao, Luoyang Museum (China)

Jing Luo, The State Bureau of Cultural Relics and Museum of Social Division (China)

Jiarui Lin, Secretary, Tianjin University (China)

\section{Session Chairs}

1 Optoelectronic Technology in Metrology

Qibo Feng, Beijing Jiaotong University (China)

2 Optoelectronic Measurement and Detection

Liandong Yu, Hefei University of Technology (China)

3 Optoelectronic Instruments and Systems I

Weihong Bi, Yanshan University (China)

$4 \quad$ Optoelectronic Instruments and Systems II

Weihu Zhou, Academy of Opto-electronics (China)

Changku Sun, Tianjin University (China) 


\section{Introduction}

The optoelectronic principle plays an outstanding role in the field of metrology and testing area as it provides an important method for the development of measurement technology. With the rapid development of information technology, the measurement technology and systems that obtain the source of information, has drawn a lot of attention. New measurement requirements appear constantly, which promotes continuous development of the optoelectronic measurement method, technology and application, to make the research on the optoelectronic measurement full of vigor and vitality.

Optoelectronic measurement research is rich in content, covering lots of areas from scientific research, manufacturing industry, to our daily life; the scope of optoelectronic measurement research expands continuously and the content continues to be more and more developed. On one hand, the traditional optoelectronic measurement research and application, represented by the background of industrial manufacturing precision measurement technology, have been constantly improving, and the concerned performances have also been improving. On the other hand, the needs of optoelectronic measurement, represented by the measurement of the digital cultural heritage protection, have been emerging ceaselessly, as well as the measuring methods and application that have developed.

More than 60 papers have been accepted into the Optoelectronic Measurement Technology and Systems branch of the OIT'2013, ranging from many research fields including optoelectronic measurement, optical instruments, spectral measurement, environment measurement, industrial measurement, optical fiber measurement, etc. These papers appropriately reflect current issues and the research level of the optoelectronic measurement field.

Jigui Zhu 
Proc. of SPIE Vol. 9046 904601-14

Downloaded From: https://www.spiedigitallibrary.org/conference-proceedings-of-spie on 26 Apr 2023 Terms of Use: https://www.spiedigitallibrary.org/terms-of-use 